\title{
Análise de macrodrenagem em áreas urbanas: soluções e propostas para a sub-bacia do Canal do Mangue
}

\author{
Bruno Borges Mamede \\ Lucas Devides Moreno \\ Juliana Diamantaras da Silva e Silva \\ Sônia Dique Fragozo \\ Marcelo Gomes Miguez *
}

\begin{abstract}
Resumo
Este artigo materializa a etapa revisão e comparação de um estudo maior sobre a drenagem de águas da sub-bacia do Canal do Mangue e as possíveis soluções a serem adotadas para o controle das cheias na região. Esta está situada entre as Zonas Norte e Centro da cidade do Rio de Janeiro (RJ). Aborda-se a urbanização da região em conjunto aos efeitos causados na drenagem local e, posteriormente, faz-se a apresentação comparativa de soluções práticas (em execução) e teóricas para solucionar os principais problemas encontrados.
\end{abstract}

Palavras-chave: Geografia Urbana; Engenharia Hidráulica; Urbanização de Sub-bacias; Micro e macrodrenagem de Sub-bacias Urbanas.

\begin{abstract}
This article materializes the review and comparison steps of a bigger study about the Mangue's Channel water drainage and its possible solutions adopted to control the regional floods. This area is placed between the North and Central zones of Rio de Janeiro's city (RJ). The region's urbanization is linked with the effects caused in the natural drainage basin and, later, a comparative presentation is made between the actual execution solutions and theoretical solutions proposed to solve the main found problems.
\end{abstract}

Keywords: Urban Geography; Hydraulic Engineering; Drainage Systems Urbanization; Micro and Macro Drainage Urban Systems.

\footnotetext{
* Bruno Borges Mamede: PEU/POLI/UFRJ (bruno.mamede@poli.ufrj.br) Lucas Devides Moreno: PEU/POLI/UFRJ (lucas.moreno@poli.ufrj.br) Juliana Diamantaras da Silva e Silva: PEU/POLI/UFRJ (juliana.diamantaras@poli.ufrj.br) Sônia Dique Fragozo: PEU/POLI/UFRJ (sonia.fragozo@poli.ufrj.br) Marcelo Gomes Miguez: PEU/POLI/UFRJ (marcelomiguez@poli.ufrj.br)
} 


\section{Introdução: proposta e objetivo}

Este artigo possui como principal objetivo o estudo da sub-bacia do Canal do Mangue, a partir da contextualização histórica combinada às alterações de curso e forma de seus principais corpos hídricos, indicando o atual cenário hidrogeomorfológico da região. Em seguida, são vistas as principais consequências dessas transformações espaciais. Posteriormente, são observadas comparativamente duas propostas de correções estruturais para a sub-bacia, sendo ambas fundamentadas no mesmo estudo, porém com aplicabilidade e visão diferenciada de alocação de esforços e recursos.

Esboça-se também uma proposta de recuperação urbana para o principal rio da região, tendo em vista o melhor aproveitamento de sua calha mimeticamente natural, favorecimento da infiltração, integração nas soluções para controle de cheias e, paralelamente, a criação de um corredor de transporte público, visando o ordenamento racional do tráfego e dos fluxos de veículos, bem como da poluição sonora, aérea e hidrológica. Ao fim, são indicadas algumas das principais conclusões percebidas das análises comparativas e resultados esperados quanto ao comportamento da drenagem urbana local.

Como metodologia, realiza-se uma ampla revisão bibliográfica interdisciplinar. Esta justifica-se pela característica do objetivo pretendido, o escopo multidisciplinar do objeto analisado, a formulação das correções e incremento na qualidade de vida via mobilidade urbana. Não apenas a urbanização da região, alterações na drenagem e a proposição de correções são utilizadas, como também foca-se um pouco na qualidade de vida que a região perdeu e pode ser recuperada. Para isto, realizam-se análises comparativas das soluções no intuito de potencializar a efetividade do projeto e, novamente, implementar a qualidade de vida local.

Ademais, são utilizados dados e mapas referentes à drenagem e urbanização da área. Metodologias próprias das ciências de Administração e Engenharia são utilizadas para a comparação e análise da formulação de propostas, além de contribuições técnico-conceituais da Arquitetura, Urbanismo e Geografia para a análise da ocupação e padrão urbanístico aplicado na região. Também são analisados conceitos e temáticas ao prisma da Biologia para tratar de questões sobre a qualidade da água. Ou seja, a partir de todo esse arcabouço teórico, pretende-se integrar aqui uma visão ampliada e expandida sobre a sub-bacia do Canal do Mangue, demonstrando que a aplicabilidade e efetividade de uma determinada solução transpassa um campo de conhecimento científico isoladamente.

A justificativa para este artigo está pautada nas recentes (e graves) mazelas percebidas pelas chuvas cada vez mais intensas e recorrentes na região, onde os efeitos demonstram-se catastróficos e causadores de calamidades públicas, tanto para a região, como para boa parte da Região Metropolitana do Rio de Janeiro (PCRJ, 2013). O principal impacto percebido nessas épocas é a paralisação (parcial ou total, dependendo da intensidade da chuva) do sistema de transporte e circulação com o alagamento das principais vias, bem como o comprometimento dos sistemas de abastecimento energético e de águas.

Atualmente, a região é objeto de intervenção por parte do poder público (municipal e federal), tanto pelas consequências e danos mencionados a uma das áreas mais populosas da cidade, a chamada Grande Tijuca (mais central polo econômico-residencial voltado para a classe média na Zona Norte da cidade) e a maior parte dos bairros na periferia da Região Central. De acordo com IBGE (2013), a região é residência de 471.041 habitantes, sendo 90,25\% residentes na Zona Norte e os outros 8,75\% residentes nos bairros da área central. 
As intervenções estruturais estão localizadas principalmente para o controle de cheias dos rios Maracanã, Trapicheiros e Joana. Também na Zona Norte localiza-se o principal e mais conhecido equipamento esportivo da cidade, utilizado na Copa do Mundo de 2014 e a ser utilizado nos Jogos Olímpicos de 2016: o Estádio Jornalista Mário Filho, conhecido como Estádio do Maracanã. De acordo com Guerra (2011), o controle de cheias se faz extremamente necessário para a manutenção da ordem urbana local e, neste contexto, pode-se mencionar a inserção da cidade no contexto de grandes eventos internacionais, como os dois eventos esportivos já mencionados.

\section{1 - Contextualização urbano-histórica da sub-bacia}

Conforme o Instituto Municipal de Urbanismo Pereira Passos (IPP), a sub-bacia do Canal do Mangue abrange uma área de $45,43 \mathrm{~km}^{2}$, limitada ao norte pela sub-bacia do Canal do Cunha, ao leste pela Baía da Guanabara, ao sul e, finalmente, a oeste pelo o Maciço da Tijuca. Os principais rios formadores da sub-bacia são o Maracanã (10,1 quilômetros), Joana (5,5 quilômetros), Trapicheiros (5,2 quilômetros), Comprido (4,5 quilômetros) e Papa Couve (3,0 quilômetros), segundo dados de IPP (2005).

No contexto urbano-espacial, esta sub-bacia está localizada nas Zonas Centro e Norte, integralmente dentro do município do Rio de Janeiro (RJ). Na Região Central, os bairros inseridos na sub-bacia são o próprio Centro, Santo Cristo, Catumbi, Estácio e Cidade Nova, enquanto na porção norte estão os bairros de Rio Comprido, Maracanã (nomeados a partir dos rios homônimos), Praça da Bandeira, Vila Isabel, Andaraí, Grajaú, Tijuca, Muda, Usina e Alto da Boa Vista.

Esta sub-bacia está inserida na macrobacia hidrográfica da Baía de Guanabara, que engloba outras tantas sub-bacias como a do Canal do Cunha, na Zona Norte da cidade do Rio de Janeiro. Também deve-se considerar que esta macrobacia engloba inúmeras outras sub-bacias na própria capital fluminense e em municípios das baixadas fluminense e niteroiense. Esta distinção é feita a partir daqui pois, mais adiante, será mencionada a proposta de CEDAE (2013) do Programa de Despoluição da Baía de Guanabara (PDBG) para análises acerca da qualidade da água na região da sub-bacia do Canal do Mangue.

Para mencionar o histórico de ocupação, considera-se como principal fonte os dados mencionados em Abreu (1987) e IPP (2005), os quais possuem um amplo acervo informativo sobre o histórico de ocupação da cidade do Rio de Janeiro. Todas as informações históricas mencionadas nesta seção são como provenientes dos autores supramencionados.

A região passou a ser efetivamente ocupada a partir da saída de corsários franceses por volta do ano 1535 e a efetiva política portuguesa de ocupação da porção oeste da Baía de Guanabara. A partir desse marco histórico, missões jesuíticas instalaram-se nos morros onde hoje está a região central da cidade e, ao longo dos séculos, expandiram-se para a atual Zona Norte, até alcançar as escarpas do Maciço da Tijuca.

Com a saída dos jesuítas na segunda metade do século XIX, a região da sub-bacia do Canal do Mangue foi objeto de intensas transformações, sendo as principais obras os aterros executados nas regiões mais baixas e alagadiças da sub-bacia. Os caminhos precisavam permitir a circulação da população e das mercadorias. O Canal do Mangue foi idealizado, ainda na época do imperador português Dom João VI, com o objetivo de drenar todo mangal de São Diogo, área pantanosa localizada na atual Cidade Nova e arredores da estação Central do Brasil. 
Este projeto visava a transformação desta área em um canal navegável para ligar a atual Praça Onze (antigo Rocio Pequeno) ao mar (na Baía de Guanabara). Sua construção foi iniciada ao final de 1857, sendo inaugurada em 1860 pelo então imperador brasileiro Dom Pedro II. Muitas foram as obras de urbanização iniciadas nessa época. A cidade toma um novo rumo de desenvolvimento urbano e as modificações estruturais passam a fazer parte do contexto urbano sem que este tenha sido pensado em sua totalidade.

De acordo com Christofoletti (1980), as bacias hidrográficas são definidas como áreas drenadas por um determinado rio ou por um sistema fluvial. Este mesmo autor é complementado por Guerra (2011) ao mencionar que os processos de urbanização são causadores de profundas modificações na estrutura de drenagem das cidades. Ao inserir novos elementos aliados a atividades antrópicas, ocorrem diversas modificações estruturais no comportamento das águas de uma determinada bacia. O planejamento dessas áreas com um foco holístico das intervenções e suas consequências é primordial no controle de cheias de uma cidade.

A partir da segunda metade do século XIX o crescimento urbano da cidade expandiu-se rumo a áreas fora do (atual) centro de forma brusca e acelerada, consequentemente, demandando grandes adequações em termos de urbanização e infraestrutura. O processo de urbanização trouxe, sobretudo a partir de 1873, para os bairros às margens do rio Maracanã, uma população de classe média alta, com várias mansões instaladas ao longo deste rio. Estas foram construídas a partir do desmembramento e loteamento de terrenos de antigas chácaras da região, em especial nos atuais bairros da Tijuca, Usina, Muda e partes de Vila Isabel e Andaraí.

A atual Praça da Bandeira, importante ponto da sub-bacia do Canal do Mangue, é a área de confluência dos cinco mais importantes rios, sobretudo em sua porção norte, tendo sua história marcada por famosas enchentes. De acordo com INEPAC (2013), em 1845 a praça foi ocupada por um matadouro, sendo então denominada Largo do Matadouro. Devido ao crescimento da cidade e a problemas de higiene, o matadouro foi transferido para o bairro de Santa Cruz, no extremo oeste da cidade, restando apenas o pórtico de entrada.

Já no século XX, no ano de 1907, ainda com objetivo de término das obras do mangal de São Diogo, é construída a avenida Francisco Bicalho como prolongamento do canal do Mangue, cuja área de aterro teve uma extensão de 1.300 metros (Brasil, 1965). O bairro Maracanã desenvolveu-se às margens do rio de mesmo nome, cuja nascente está no Maciço da Tijuca e transcorre, de montante a jusante, os bairros de Alto da Boa Vista, Usina, Muda, Tijuca, Maracanã e Praça da Bandeira, até sua foz no próprio Canal do Mangue. A delimitação efetiva (e atual) desses bairros foi estabelecida pelo Decreto Municipal 3.158/81.

A síntese desse processo nos dias atuais reflete o subaproveitamento das pontecialidades existentes: o rio Maracanã tornou-se um grande canal receptor de grande parte dos escoamentos superficiais e corpos hídricos da sub-bacia, a impermeabilização do solo e poucos pontos de infiltração dificultam o escoamento das águas superficiais, bem como a rede de drenagem antiga está muito aquém da atual necessidade demandada.

Segundo Abreu (1987), Miguez (2001), D’Altério (2004), Guerra (2011) e IPP (2005), todo o conjunto desta sub-bacia deve ser pensado de modo que as medidas estruturais possam devolver características já existentes no período anterior a sua urbanização (como a devolução da foz original para alguns rios), bem como a instalação estratégica de diversos elementos que possam reter as águas pluviais em seu ponto máximo para, posteriormente, devolvê-las aos rios paulatinamente sem causar os atuais alagamentos percebidos na região.

Também deve-se considerar que, estas alterações não apenas garantem a segurança e a normalidade (por esta entende-se a diminuição do risco de interrupções críticas) da ordem 
urbana, mas também são responsáveis por ampliar a qualidade de vida da população local. Projetos alternativos podem ser pensados futuramente como o reaproveitamento dessas águas armazenadas para tratamento e uso como limpeza e conservação de áreas urbanas, reduzindo a demanda local por água tratada em épocas de grandes chuvas. Ao buscar este objetivo, de acordo com Rossi (2003), pode-se considerar como urbanização sustentável a estratégia de aplicação dessas medidas que buscam o uso mais racional dos recursos e aproveitam de maneira mais eficiente a infraestrutura existente com as adequações pertinentes.

\section{2 - Situação atual e principais problemáticas}

Como já exposto, a ocupação da cidade do Rio de Janeiro foi sendo realizada na medida em que as obras de infraestrutura melhoravam as condições de vida. Como nas grandes metrópoles, a ocupação do espaço urbano acaba por refletir a situação socioeconômica da cidade. No caso da cidade do Rio de Janeiro, essa situação fica mais evidente por ela ter sido durante mais de dois séculos a capital do país, ditando assim a moda metropolitana brasileira (Santos e Bronstein, 1978).

De acordo com Abreu (1987), com alterações urbanísticas ao longo dos anos, o rio Maracanã passa a sofrer constantes intervenções. Nos anos 1950 sua canalização foi expandida e, a partir de então, não é mais capaz de comportar o volume de água atual que a sub-bacia recebe, gerando inúmeras inundações. Acrescenta-se a este fato, entre algumas das intervenções, a interligação dos rios Comprido, Joana e Trapicheiros ao rio Maracanã. Dessa forma, a contribuição desses três rios ao Maracanã acrescentou volumes e vazões muito superiores àqueles originalmente observados sem que seu dimensionamento fosse devidamente readequado ao (novo) canal para comportar tal volume.

\subsection{Ocupação urbana da sub-bacia do Canal do Mangue}

Devido aos diversos aterros sofridos e às ações antrópicas de alteração dos cursos dos rios (principalmente), a bacia teve o seu sistema fluvial modificado. Os rios tiveram as suas margens ocupadas e suas calhas, modificadas. Alguns trechos desses rios correm por tubulações sob as ruas e avenidas dos bairros. O maior exemplo das intervenções urbanas na bacia é o rio Maracanã que atualmente é a foz dos rios Joana e Trapicheiros, sem a devida adaptação de seu canal. Com o seu entorno urbanizado, o rio sofre com a impermeabilização do solo e sua calha não suporta as grandes precipitações.

Com a ocupação das margens destinada à parte mais abastada da sociedade local, a população de baixa renda inicia a ocupação das encostas de forma precária que, ocorrida desordenadamente e somada às medidas de urbanização do entorno, resultam, atualmente, em problemas frequentes com as cheias dos principais rios. As favelas proliferaram e ocupam boa parte das encostas em resposta à valorização da terra trazida por implementos e melhorias no sistema de drenagem com as obras de macrodrenagem mencionadas anteriormente. Esta afirmação pode ser observada no depoimento de um antigo morador do Borel, no bairro da Tijuca.

Vim do Espírito Santo com sete anos de idade e cheguei aqui no Borel em 21 de outubro de 1938 [...]. Nós passávamos muita dificuldade lá e meu pai resolveu vir para o Rio de Janeiro. Mas quando nós chegamos aqui tivemos uma surpresa. Viemos para o meio do mato. Isso aqui era tudo mato, não tinha nem caminho para se andar. Peguei isso aqui com apenas três moradias, três barracos [...]. Meu pai alugou um. Tinha um que era uma 
chácara de bananas, quem tomava conta era a d. Maria Portuguesa. E depois tinha um outro embaixo, família do Nilzo. Mas depois nós começamos a ser perseguidos pelos grileiros que existiam aqui nos anos 50. Toda semana vinha a polícia para tirar a gente daqui [...]. Vimos lutando e conseguimos isso aqui, com muita força e muito esforço (Depoimento de José Calegario, antigo morador do Morro do Borel). (IBASE, 2006)

\subsection{Planos para a moderna cidade do Rio de Janeiro}

A cidade foi ocupada paulatinamente sem um plano diretor que ordenasse e controlasse esta ocupação. Algumas das principais intervenções urbanas que constituíram exemplos da fase planejamento lato sensu de planejamento para a cidade do Rio de Janeiro:

- Reforma Passos (1906)

- Plano Agache (1930)

- Primeiro Plano Diretor Municipal (LCM 16/92)

Ficou reservada ao século XX a ordenação da cidade, que até era então sinônimo de epidemias. Em seu início, com o prefeito Pereira Passos, a cidade começou a ser reformada e readequada para novas demandas, com grandes obras de transformação durante o seu mandato. De acordo com Abreu (1987) essas reformas foram largamente inspiradas naquelas ocorridas em diversas grandes cidades europeias ao final do século XIX, de caráter sanitarista e higienista, focando o controle de endemias.

Durante o governo do prefeito Antônio Prado Junior (1926-1930), o arquiteto francês Alfred Agache foi contratado para o projeto de um plano diretor para a cidade do Rio de Janeiro. Este, doravante denominado Plano Agache, trouxe para a cidade do Rio de Janeiro uma atenção especial para o embelezamento, ao basear-se no modelo parisiense de urbanização. Sua atuação foi principalmente para as zonas Sul e Centro da cidade, concentrando nessas áreas as soluções propostas de saneamento e erradicação de favelas. A partir dessa época o planejamento urbano foi instituído e conhecido como ocorre atualmente.

Em 1992, a Câmara Municipal do Rio de Janeiro aprova o Plano Diretor Decenal da cidade, através da Lei Complementar (PLC) 16/92. Estabeleceu-se assim uma nova política urbana para a cidade (PCRJ, 2013), ao instituir medidas como a participação popular nas etapas do processo de planejamento. Contudo, o novo plano não foi bem aceito pelo Executivo municipal. Ainda, de acordo com PCRJ (2013), no ano de 2011, mediante a perspectiva de realização de grandes eventos internacionais, a cidade recebe um novo plano diretor, o qual modifica o zoneamento da cidade criando áreas de interesse destinadas ao preparo da cidade para a realização dos eventos.

A partir de uma análise sintética dos planos diretores citados, é possível inferir que ainda há uma grande carência de abordagem sistêmica para o direcionamento básico de suas políticas e recursos. Percebe-se que os interesses político-econômicos sobrepujaram a técnica e a tecnologia na avaliação do contexto urbano, não apresentando soluções integradas ao cotidiano da cidade. A drenagem urbana é um exemplo da desconexão dos planos com a realidade da cidade, sendo sempre tratada com soluções isoladas, sem integrar efetivamente a legislação (local) de ocupação e uso do solo, bem como a forma das construções. Conforme observado, o poder público não apresenta um grande interesse normativo e/ou jurídico-legal para esta temática.

\subsection{Programa de Despoluição da Baía de Guanabara (PDBG)}

Não é pertinente desconsiderar a questão da perda de qualidade da água de corpos hídricos, bem como o constante assoreamento de seus leitos, a ocupação irregular de suas margens e inúmeras outras graves questões ambientais que colaboram para que a população 
dos bairros que compõe a sub-bacia perca sua identificação com os rios, que acabam por ser considerados pela população como valóes. O principal sistema receptor dos esgotos da região é o Tronco Alegria, integrante do Programa de Despoluição da Baia de Guanabara (PDBG) e composto, além de seus troncos coletores, pela Estação de Tratamento de Efluentes de mesmo nome (ETE Alegria). Durante a confecção deste artigo não houve tempo hábil para estabelecer estimativas sobre a cobertura e nível de atendimento à população da região, mapeamento das redes coletoras e volume tratado na ETE Alegria para estabelecer uma comparação conclusiva que comprovasse qual o percentual de esgotos da nossa área de influência é direcionado ao sistema de tratamento. Contudo, em face ao proposto neste plano por CEDAE (1995) e a estimativa de população da região de acordo com IBGE (2013) e IPP (2005), em uma avaliação tópica, nota-se que o objetivo de atingir a totalidade da população presente na região ainda está bem aquém do esperado.

Segundo o relatório do PDBG, disponibilizado pela Companhia Estadual de Águas e Esgotos (CEDAE), o Sistema Alegria é composto pelos troncos coletores de Alegria, Tijuca, São Cristóvão e Avenida Brasil, já executados e em operação, além de troncos coletores Faria Timbó, Manguinhos, Galeria de Cintura da Maré, Cidade Nova e subsistemas complementares, ainda a serem executados. Desta forma, observa-se atualmente que o Canal do Mangue ainda é o corpo receptor de esgotos in natura advindos destas áreas.

A partir dessas informações, compreende-se que os alagamentos, além dos pontos já abordados, trazem à tona questões de saúde pública: com o transbordamento desses corpos hídricos, altamente comprometidos em sua qualidade ambiental e sanitária, disseminam-se inúmeras doenças de veiculação hídrica. Também ocorre contribuição não apenas de esgotos sanitários, mas de resíduos de todo tipo, sem coleta e disposição final adequados, advindos das inúmeras favelas que circundam os bairros que compõem a sub-bacia do Canal do Mangue, entre elas Borel, Formiga, Andaraí, Mangueira, Turano, entre outras.

Além dos esgotos, despeja-se lixo de toda e qualquer origem, assoreando os leitos destes rios, o que agrava ainda mais as questões de saneamento ambiental, distribuição equitativa de infraestrutura e habitações para toda a população, bem como compromete o sistema de saúde que não está intrinsecamente correto ao sistema de drenagem da região. Reforça-se assim o enfoque multidisciplinar, transversal e sistêmico de soluções de drenagem, pois este é um dos componentes indissociáveis do sistema urbano.

Não apenas o direcionamento dos rios para a composição de um novo canal principal que não foi projetado para suportar um supervolume de águas, tanto em seu curso normal como nas épocas de maior fluxo de águas das chuvas, o deságue deste novo super Rio Maracanã ocorre no ponto mais ao norte do Canal do Mangue, onde as águas são levadas para a Baía de Guanabara. Contudo, ao projetar esta interligação, não se considerou o fato de que parte das águas dos rios Comprido (Norte) e Papa Couve (Centro) já é destinada a este canal, que foi originalmente projetado apenas para drenar uma região pantanosa, de baixíssima altitude e naturalmente alagadiça.

Desta maneira, Miguez (2001) e D’Altério (2004) consideram um efeito hidráulico cumulativo em épocas de grandes fluxos hídricos, pois a baixa potencialidade de escoamentos do Canal do Mangue e do Rio Maracanã, combinada à baixa atitude da área de deságue em áreas que eram naturalmente alagáveis, resulta em alagamentos primários nas áreas do canal e a acumulação de volumes ao longo do super curso do rio, extravazando para as vias locais em seu curso e de seus contribuintes. 
Assim, segundo estes autores e diversos outros consagrados em Engenharia Hidráulica e de Saneamento, o sistema de projeção imperfeita dos super canais do Mangue e Maracanã não apenas prejudica o escoamento das águas superficiais como também cria um sistema de efeitos em looping, onde apenas a acumulação de volumes prejudica gradualmente a ordem urbana nas áreas sob a influência desta sub-bacia.

\section{3 - Propostas corretivas de drenagem}

Atualmente, Rio Águas está implantando algumas medidas corretivas estruturais na região para mitigar os efeitos das grandes cheias ocorridas, sobretudo nos meses de dezembro a março. De acordo com o projeto de drenagem apresentado (Rio Águas, 2013), as principais intervenções encontram-se nos rios Maracanã e Joana, principais focos de transbordamento e alagamento no período supracitado.

Quando soluções de drenagem de uma bacia hidrográfica são discutidas, não é indicado ater-se apenas em um ou nos principais rios para obter resultados eficientes. Faz-se necessária a visão sistêmica da bacia: trabalhar um conjunto de elementos que contribuem para que esta apresente (novas) características desejadas após a intervenção. Canholi (2005) menciona que os efeitos conjuntos de rios de duas ou mais bacias fornecem vazões distintas ao analisá-las em conjunto.

A implantação de um reservatório em determinado ponto da bacia 2 (por exemplo) ocorre como medida para solucionar problemas de enchentes na região em questão. A solução cumpriu seu principal papel: acumular volume na confluência das bacias 1 e 2, redistribuindo seu volume de água em um maior espaço de tempo. Com isso, reduz-se à metade sua vazão. Como esta medida foi pensada de maneira isolada, pode ocorrer como efeito colateral o aumento no volume de água na sub-bacia hidrográfica 1, além de acarretar um acréscimo de vazão de pico ( $\triangle$ Qpico) para a bacia como um todo. Em suma: o fato de ter solucionado um problema de maneira isolada acarretou (e agravou) outros dois para o conjunto do sistema hidrográfico.

Aqui será apresentado um conjunto de medidas que podem mitigar problemas de enchentes. Basicamente elas são divididas em medidas estruturais e não estruturais. Como o ambiente estudado já se encontra em situação bem crítica, isto é, já existem diversas medidas estruturais que alteraram a drenagem urbana desordenadamente, a análise proposta priorizará medidas estruturais, pois, apesar de mais caras e com aplicação mais lenta, acredita-se que a sua aplicação inicial deverá reverter um pouco a situação atual para um patamar mais passível de controle e aplicação de medidas não estruturais em paralelo.

Segundo Miguez (2001), a Praça da Bandeira está em uma região cuja altitude é muito baixa, sendo alguns pontos até mesmo abaixo do nível do mar. Paralelamente, a contribuição dos rios que deságuam no Canal do Mangue (Rio Joana, Rio Maracanã, Rio Trapicheiros, Rio Comprido e Rio Papa-Couve) expõe os maiores problemas de drenagem da região.

Na montante dos rios Joana, Maracanã e Trapicheiros, focam-se as medidas estruturais com características filtrantes, para diminuição do volume de água que corre em direção ao Canal do Mangue. Algumas são: uso de trincheiras de infiltração nos estacionamentos, praças e pontos de ônibus, calçadas, bem como pavimentos permeáveis em algumas avenidas de pequena circulação. Estas devem ser complementadas com outras medidas não estruturais, como a conscientização da população (mostrando e exemplificando os danos causados 
pela introdução de resíduos nos rios), monitoramento de ligações clandestinas nas redes de drenagem, apresentação dos danos causados pelo processo de impermeabilização do solo, incentivo ao plantio de árvores, pois, além contribuir para um clima mais ameno (conforme percebido nas áreas mais próximas ao Parque Nacional da Tijuca), a vegetação retém parcela significativa do volume de água proveniente das chuvas.

Medidas infiltrantes são importantes para diminuição de enchentes no Canal do Mangue, destino final de grande parte das águas da sub-bacia, porém realizadas isoladamente possuem eficiência muito limitada e restrita, o que confirma a necessidade de priorizar medidas estruturais de retenção de águas.

Para a retenção são utilizados dois estudos, com propostas muito próximas, porém de escopo e aplicabilidade um tanto distintos. O primeiro é o projeto já em execução por Rio Águas desde 2011 e o segundo, a proposta apresentada por Miguez (2001) em sua tese de doutorado. Resumindo, enquanto este consiste na construção de pequenos reservatórios e intervenções para o armazenamento de água, para obter redução de vazões, aquele destina-se à construção de grandes reservatórios para reter o mesmo volume de águas pluviais.

As ações apresentadas por Miguez (2001) estão assim distribuídas:

- Reservatório de amortecimento temporário, no Parque Recanto do Trovador, no Grajaú, coletando água das várias encostas de seu entorno, e recebendo também a enchente do Rio dos Urubus, desviada, por projeto específico, para seu interior, na sub-bacia do Rio Joana;

- Reservatório de amortecimento no Rio Jacó, um dos formadores do Rio Joana;

- Reservatório de amortecimento no Rio Perdido, o outro formador do Rio Joana;

- Intervenção na rua Ferreira Pontes, na sub-bacia do Rio Joana;

- Reservatório de amortecimento no Rio Andaraí, última intervenção do conjunto proposto para a sub-bacia do Rio Joana;

- Reservatório de amortecimento no trecho alto do Rio Maracanã;

- Reservatório de amortecimento no Rio São João, afluente do Rio Maracanã, pela margem esquerda;

- Reservatório de amortecimento no Rio Agostinho, afluente do Maracanã, pela margem direita;

- Reservatório de amortecimento no Rio Cascata, afluente do Maracanã, pela margem direita;

- Reservatório de amortecimento no Rio Caxambi, afluente do Maracanã, pela margem esquerda;

- Conjunto de sete soleiras de admitância, na calha do Rio Maracanã, ainda no seu trecho médio-alto;

- Reservatório de amortecimento no trecho alto do Rio Trapicheiro;

- Reservatório de amortecimento Poço dos Esquilos, no primeiro afluente, pela margem direita do Rio Trapicheiro;

- Conjunto de três soleiras de admitância, na calha do Rio Trapicheiro, na região do seu trecho médio-alto;

- Reservatório de amortecimento da Rua Bom Pastor, próximo ao morro do Salgueiro, na sub-bacia do Rio Trapicheiro;

- Reservatório de amortecimento do Hospital Evangélico, próximo ao morro do Salgueiro, na sub-bacia do Rio Trapicheiro;

- Reservatório de amortecimento da Rua Valparaíso, próximo ao morro do Turano, na sub-bacia do Rio Trapicheiro; 
- Reservatório de amortecimento da Chacrinha, próximo ao morro do Turano, na subbacia do Rio Trapicheiro;

- Reservatório de amortecimento da Rua Maestro Villa-Lobos, próximo ao morro do Turano, na sub-bacia do Rio Trapicheiro;

- Reservatório de amortecimento no trecho alto do Rio Comprido;

- Reservatório de amortecimento no Rio das Bananas, afluente pela margem esquerda do Rio Comprido.

Estas medidas são muito bem vistas, pois, além de proporcionar facilidade de manutenção, pequenas obras possuem estimativas de custos mais próximas à construção efetiva (baixa profundidade dos reservatórios, facilitando no ato da escavação). Ou seja, sabe-se com maior precisão o tipo de material e infraestrutura já construída presente na área de obras diante da pequena profundidade escavada. Menciona-se também que, na probabilidade de falha no funcionamento de algum reservatório, existem outros em boa quantidade para redistribuição do volume extra gerado por esta disfunção. Ademais, a falha de um pequeno reservatório possui um impacto menor ao funcionamento de todo o sistema do que de outros maiores, comprometendo menos a capacidade de armazenamento global.

Já o projeto de Rio Águas, atualmente em execução, contempla a mesma concepção da solução anterior, porém ocorre uma diferenciação no tocante aos reservatórios. Distinto do anterior, que previa diversos pequenos pontos de retenção, este determina a construção de três grandes reservatórios:

- Reservatório na Praça Niterói, em Vila Isabel;

- Reservatório na Praça Varnhagen, na Tijuca;

- Reservatório na Praça da Bandeira, no bairro homônimo.

Com a diminuição da quantidade de reservatórios, essas obras mudam de porte, agravando-se diversos problemas e implicações para sua manutenção e limpeza, devido a sua própria natureza: tais reservatórios possuem em média 40 metros de profundidade, acessados por elevadores ou estruturas de deslocamento vertical. Isto impossibilita a entrada de grandes equipamentos para limpeza e conservação. Apesar dos estudos prévios de sondagem do solo, existe grande probabilidade de encontrar elementos não previstos em escavações deste porte, encarecendo e atrasando o prazo para entrega da obra. Adicionalmente, caso algum destes reservatórios apresente problemas de operação em horários de maior demanda, há uma perda imediata de pelo menos 30\% na sua capacidade de armazenamento e retenção de águas pluviais.

Para comparação efetiva entre as propostas de Miguez e Rio Águas, pode-se utilizar a ferramenta chamada Planilha $5 \mathrm{~W} 1 \mathrm{H}$, siglas em inglês de um processo esquemático para o levantamento de questões e o caminho em que cada uma delas poderá ser resolvida (What, Who, When, Where, Why e How). Segundo Campos (2003), a praticidade de uso e aplicabilidade em organizações de qualquer porte é sua principal vantagem, pois não necessita de equipe técnica especializada. Contudo, necessitam-se pessoas treinadas nesta metodologia de processo para organizá-lo. Para confeccionar uma planilha desse tipo, é necessário conhecer as causas do problema e realizar cada etapa de maneira cuidadosa sempre de forma correta.

Como já apresentado anteriormente, duas propostas de contenção de cheias do Canal do Mangue foram simuladas e as seguintes questões foram levantadas:

- O problema em questão consiste em armazenar um volume total de água da chuva para minimizar a questão das cheias na região da sub-bacia do Canal do Mangue. 
Com a ferramenta administrativa, percebe-se uma ampla distribuição do problema na solução proposta por Miguez (2001), dividindo-o em 21 benfeitorias. Apesar de envolver uma grande área de intervenção, torna a solução mais fácil de ser executada, e reduz a vulnerabilidade, caso ocorram problemas técnicos durante a operação dos equipamentos.

- Como o volume de água que deverá ser armazenado é o mesmo da solução anterior, percebe-se que, para tratativa do mesmo problema, Rio Águas têm soluções mais ousadas de armazenamento, dividindo o volume total em apenas três reservatórios. O fato de utilizar uma área muito menor para esta tratativa demanda escavações mais profundas, pois como já dito anteriormente os volumes de captação de água são os mesmos.

Assim, para Campos (2003) as ferramentas administrativas são importantes agentes para solucionar e viabilizar projetos de qualquer complexidade. Estas ferramentas têm como prerrogativa fragmentar uma questão complexa em diversas soluções simples capazes de mitigar eventuais empecilhos no processo de implantação das soluções.

Complementarmente, Chiavenato (2005) aplica o conceito de vantagem competitiva como um ponto indicador na tomada de decisão. Segundo ele, ao admitir que ambas as soluções possuem vantagens e desvantagens intrínsecas a sua aplicação, a ponderação de ambos os fatores é capaz de determinar o maior benefício de sua implantação. Este benefício denomina-se vantagem competitiva, ou seja, comparativamente às outras soluções disponíveis, aquela capaz de apresentar o melhor benefício (seja de aplicabilidade técnica, mobilização de recursos, solução tecnológica, seja de quaisquer outros fatores adicionais) deverá ser a solução aplicada.

Conforme já mencionado, ao verificar ambas as soluções pelo método apresentado por Campos (2003) e Chiavenato (2005), percebe-se que, no contexto geral, o benefício maior da solução de Rio Águas está na pequena mobilização de espaço para intervenções, enquanto aquela apontada por Miguez preza pelo funcionamento de um sistema integrado de forma pulverizada. Ao perceber a vantagem de intervenções menores, a solução de Rio Águas apresenta-se como mais eficiente em não atrapalhar o cotidiano da cidade, contudo, mesmo com um número maior de intervenções, o sistema busca um equilíbrio e regulação própria, sendo necessária maior intervenção inicial e menor conservação, distintamente oposta à outra solução apresentada.

\section{4 - Corte transversal com a mobilidade urbana}

Ao buscar o equilíbrio da rede de drenagem de bacias hidrográficas, retoma-se o diálogo sobre a implementação da qualidade de vida dos habitantes da região sob intervenção. Desta maneira, utilizando-se de uma visão sistêmica sobre a bacia, é possível pensar em diversos usos e formulações múltiplas de aproveitamento dos recursos disponíveis de forma integrada ao controle de cheias e racionalização do (atual) problema de escoamento das águas.

Algumas das propostas apresentam intervenções com diversos outros setores presentes na infraestrutura urbana: abastecimento energético e hídrico, limpeza urbana, educação, saúde, lazer e entretenimento, mas, principalmente, um setor-chave para o modo de vida metropolitano, a mobilidade urbana. 
Ferraz (2004), Bannister (2010) e Silva (2012) são enfáticos ao mencionar que as vias de transporte urbano, tanto público como particular, são tão importantes para a determinação dos fluxos e aplicação de recursos em um dado espaço urbano a ponto de comparar a rede de transportes presente às veias e artérias do corpo humano que, mesmo não desempenhando o papel primário de outros órgãos vitais (como cérebro, coração e pulmões, por exemplo), são as responsáveis pela estrutura de funcionamento suporte dos mesmos. Ou seja, em ambas as situações, existe uma forte relação de codependência, sendo o desempenho de uma parte fundamental para a outra, de forma harmônica e recíproca, garantindo assim a boa funcionalidade e equilíbrio do sistema.

Rossi (2003) complementa essas afirmações ao mencionar que a livre circulação de pessoas pelo espaço urbano é uma forma justa de uso deste espaço, implementando a liberdade individual e a qualidade de vida da população. Entretanto, a mesma autora afirma que isto deve ser realizado de forma eficiente e ponderada, tendendo, assim, à potencialização máxima dos recursos existentes, em equilíbrio com o meio natural presente.

Assim, para a elaboração de um projeto que, simultaneamente, integre as distintas áreas urbanas da área sobre intervenção, facilite o escoamento e infiltração das águas superficiais e implemente a qualidade de vida local, exige-se uma solução que não seja apenas estrutural, mas também não estrutural. Ou seja, ao mesmo tempo em que a estrutura física da infraestrutura de transporte sofre alterações, também é preciso atuar no comportamento da população, focando principalmente em seu locus vivendi: a maneira como o deslocamento é feito deve mudar ao longo dos anos, garantida por modos e estrutura eficientes e suficientes para manter (ou até mesmo aumentar) o conforto geral de suas viagens.

Ao perceber que as soluções estruturais de drenagem já estão sendo implementadas, como o desvio do Rio Joana para o deságue direto na Baía de Guanabara (retornando a sua foz de origem e não contribuindo mais em volume, fluxo e vazão para o Rio Maracanã) e a construção de reservatórios retentores de parcela das águas pluviais em excesso, sugere-se uma solução de rápida aplicabilidade que, ao mesmo tempo, possa atender a demandas de transporte público e drenagem urbana da região.

Dessa forma, propõe-se a construção de um corredor de circulação para veículos rodoviários ao longo de grande parte do curso do Rio Maracanã, interligando estruturas de transportes já existentes, racionalizando fluxos e permitindo interfaces com a atual rede já existente. Baseado no método decisório multicritério de Silva (2012), porém aplicado à região estudada, opta-se pela construção de um eixo troncal tipo bus rapid transit que, a partir deste ponto, será denominado BRT Maracanã.

Antes de mencionar os aspectos próprios de infraestrutura de transportes, sugere-se de maneira complementar ao projeto de Miguez (2001) - o qual visa garantir a qualidade e correta vazão das águas no Rio Maracanã a partir do monitoramento de ligações clandestinas na rede pluvial (que deságua neste corpo hídrico) e a interligação dos reservatórios retentores ao mesmo (retardando as possíveis cheias que ocorrem nos períodos de chuvas mais intensas) que o piso presente no assoalho fluvial e nos degraus presentes dentro da calha do rio sejam substituído por outros de pequeno potencial de infiltração.

No tocante aos degraus de concentro, poderiam ser substituídos por materiais próximos aos sedimentos naturais encontrados nos rios que facilitem a permeabilidade de parte das águas. Contudo, para que o solo não permaneça encharcado e comprometa sua resistência estrutural, sugere-se um sistema mecânico em que a permeabilidade seja possível apenas nos períodos de maior fluxo dentro do rio, permitindo assim sua infiltração até que o volume seja normalizado. 
No tocante ao corredor propriamente dito, o objetivo é aproveitar grande parte da estrutura viária existente, com algumas adaptações, ordenando o fluxo de veículos para uma nova via estrutural (ou mesmo a formação de um novo eixo nevrálgico) para a região, interligandose, por um sistema de média capacidade, esta porção da Zona Norte ao Centro da cidade.

A escolha de um sistema de média capacidade é respaldada na oferta já existente de meios de alta capacidade já disponíveis na região, através da passagem de duas linhas de metrô e cinco de trem presentes. Com isso, a passagem desse corredor possui um caráter estruturador do transporte rodoviário, permitindo a integração aos outros modos, e não o de compor o principal corredor de transporte público da região.

Admite-se aqui, baseado na metodologia multicritério adotada por Silva (2012), amplamente pautada nos estudos, afirmações e diretrizes teóricas apontadas por Ferraz (2004) e Bannister (2010), que a matriz de oferta de transportes deve ser diversificada, sendo os maiores fluxos direcionados aos meios de maior capacidade para destinos mais distantes, enquanto o transporte rodoviário cumpre a função de ordenamento, alimentação e estruturação racional deste sistema, principalmente pela sua vantagem competitiva: flexibilidade de percursos atendendo localidades mais específicas do que os outros meios.

Ao utilizar o viés de aproveitamento da estrutura existente, aliado à racionalização do sistema de circulação em conjunto com as soluções de drenagem implantadas, este estudo está pautado em dois pilares conceituais: o primeiro é o viés teórico-conceitual de ordenamento de transportes, baseado no maior aproveitamento da rede e capacidade disponível, enquanto o segundo pauta-se no melhor aproveitamento de estruturas de drenagem e a retomada da identidade local. Assim, o primeiro pilar é pautado pelos estudos de Bernick e Cervero (1996) e Serrano (2005), enquanto o segundo é percebido nas análises de Paik (2013) juntamente a projetos e dados da Prefeitura da Cidade Especial de Seul (Seoul Teukbyeolsi) (2013), respeitando-se as características onde as proposições foram inicialmente trabalhadas.

No primeiro pilar estão os estudos de ordenação e racionalização de sistemas de transportes isolados e/ou caóticos. Bernick e Cervero (1996) analisaram políticas de implantação em algumas das principais cidades estadunidenses e concluíram que o melhor aproveitamento, tanto para usuários como para operadores, ocorre quando os sistemas convergem para distribuir proporcionalmente as viagens entre os meios de maiores e menores capacidades. Citam inclusive que cidades como Nova York, com uma extensa rede metro-ferroviária metropolitana, possuem pouca demanda de transporte rodoviário devido às inúmeras integrações presentes em todo o sistema, enquanto o extenso parque rodoviário presente em Los Angeles dificilmente atenderá a toda a demanda prevista utilizando apenas veículos de baixa e média capacidade no transporte público e pressionando o usuário a utilizar o transporte privado.

Serrano (2005), ao estudar a cidade de San Juan, em Puerto Rico, menciona que há uma grande carência de eixos de integração entre o centro da cidade e os bairros locais. Ao estudar a Avenida de Diego como eixo de integração para o bairro de Santurce, propõe não apenas a criação de um eixo nevrálgico que interligue o Trén Urbano (metrô) ao Metro Urbano (BRT) e sistema alimentador local, mas que isto ocorra na principal avenida comercial, onde a maior parte das viagens é gerada. Com isso, a oferta estará direcionada para atender a demanda concentrada (e induzida) ao novo eixo, evitando a oferta desnecessária em locais onde o atendimento é baixo e pouco presente.

Contudo, muitos políticos e estudiosos possuem largas ressalvas na transformação de áreas urbanas e intervenções longas e profundas. Paik (2013), ao analisar a grande transformação ocorrida no Rio Cheonggyechon, um dos tributários do Rio Han (principal da bacia 
de Han) com 5,8 quilômetros de extensão, menciona que Seoul Teukbyeolsi conseguiu inserir um corpo hídrico altamente degradado com vias de transporte saturadas, causadores de grande poluição e decréscimo da qualidade de vida na cidade de Seul, Coreia do Sul, em um exemplo de pós-modernidade desejada, com uso maximizado racional do solo e contribuinte de melhores condições de vidas para os cidadãos locais.

O projeto de revitalização deste rio, encampado pelo então prefeito Lee Myung Bak (posteriormente presidente do país), foi a maior intervenção urbana promovida pelo poder público em áreas densamente ocupadas na Coreia do Sul. Ele previa a retirada total da via expressa (tanto o trecho elevado como aquele em nível inferior presente nas margens então modificadas por obras civis) ali presente e sua consequente substituição por meios de alta capacidade que utilizassem energia limpa e renovável, tratamento de toda água até que atingisse níveis de potabilidade e consumo humano, bem como a criação de um enorme parque fluvial entregue para o lazer da população local. Ao custo de US\$ 380 milhões de dólares estadunidenses (R\$ 491 milhões de reais em valores da época) e 40 meses de obras, este grande projeto foi entregue à população. No lugar das pistas expressas para automóveis, a empresa estatal de ferrovias Korail abriu linhas locais e metropolitanas no entorno do parque, tanto em nível de solo como subterrâneas. Parte do tráfego da expressa presente foi desviado para uma via anelar no entorno do parque, com capacidade de tráfego bem inferior à de sua antecessora.

Observado por Easley e Kleinberg (2010), a construção deste parque e a investida da Korail derrubaram o grande paradigma dos engenheiros sul-coreanos de que a abertura de novas vias seria incapaz de absorver a contínua demanda por espaço para deslocamento. Assim, este princípio, que expressa exatamente o Paradoxo de Braess, foi amplamente repensado ao se perceber como resultados o aumento no número de viagens e a mudança no locus vivendi da população - que enxergou aquela área como prioridade e aderiu ao novo modelo de transporte proposto -, bem como a percepção de um símbolo da identidade urbana local.

Desta maneira, seguindo este exemplo, porém com uma escala de alcance e intervenção muito menor, o BRT Maracanã pretende apresentar, em conjunto com as outras soluções mencionadas e outras de posterior implantação, uma alternativa ao deslocamento de passageiros entre o Centro e a Zona Norte, bem como ordenar os fluxos desta segunda para outras porções da cidade, como a Zona Sul, além de outros bairros da própria Zona Norte.

Com extensão de 10 quilômetros, o corredor inicia-se no Terminal Usina, seguindo em via compartilhada por 2,8 quilômetros até a Avenida Maracanã, transcorrendo toda a sua extensão até o Viaduto das Forças Armadas (5,0 quilômetros), seguindo pelas faixas BRS da Avenida Presidente Vargas até o Terminal Central do Brasil, num trecho de 22 quilômetros.

Para esta operação sugerem-se 05 terminais de ônibus e 12 paradas locais. Sendo os terminais:

- Grande Terminal Central do Brasil, localizado onde hoje há um pequeno terminal municipal na Avenida Presidente Vargas, com sua ampliação em praças subutilizadas no entorno e integração aos sistemas de metrô e trens suburbanos.

- Grande Terminal Cidade Nova, localizado imediatamente ao lado da estação Cidade Nova do metrô, utilizando áreas subutilizadas em ambos os lados da Avenida Presidente Vargas

- Terminal São Cristóvão, localizado próximo à estação São Cristóvão do metrô (com integração ao mesmo), nas proximidades do Rio Maracanã em áreas de uso diversos com baixa ocupação.

- Terminal Saens Peña, localizado nas proximidades das praças Lamartine Babo e Luis La Saigne, concentrando paradas reguladoras de linhas municipais e metro- 
politanas já existentes e permitindo integração gratuita com linhas que atinjam a estação Saens Peña do metrô.

Terminal Usina, localizado no terminal já existente, com reforma e readequação da estrutura já existente.

Todos os terminais contariam com banheiros, locais para compra de bilhete eletrônico e recarga dos mesmos, espaços de espera para passageiros e piso rebaixado totalmente acessível a PNE. Todos os veículos possuirão piso rebaixado em nível da calçada, biarticulados com capacidade máxima de 235 passageiros, ar condicionado, poltronas diferenciadas e sistema de entretenimento.

Toda a estrutura física é determinada em função de um veículo de 28 metros e 40 toneladas de peso total carregado. As estações deverão ter 35 metros de comprimento, com design próprio do projeto, assentos de espera e cabines de compra e recarga de bilhetes eletrônicos. A faixa de rolamento será construída em piso rígido para evitar a manutenção em curtos períodos.

Ressalta-se que toda esta estrutura está preparada para atender uma demanda máxima de 30 mil passageiros. Além disso, quando ocorrer um aumento da capacidade máxima de atendimento, a estrutura já permite a adequação para veículos ferroviários de maior capacidade, a partir da redução no número de paradas, mas havendo a permanência dos terminais mencionados.

Também é importante indicar que, para a materialização desta proposta, são demandados diversos estudos complementares até a devida confecção do projeto executivo. Contudo, busca-se aqui a adequação de uma solução de transporte para a maximização de uso da via e a reordenação de fluxos para reduzir a quantidade de veículos em circulação, congregando interdisciplinar, transversal e sistemicamente os projetos de drenagem e mobilidade na região. Conforme mencionado, ambos são componentes de um sistema urbano que necessita ser analisado de forma integrada.

\section{Conclusões e reflexões}

Ao perceber que a região em questão necessita de soluções urgentes, o poder público apresenta-se mais ativo aos problemas da região e, também, procura adequar a cidade do Rio de Janeiro para os grandes eventos. Independente da solução adotada, a região já está tendo um grande ganho ao ver seus problemas reconhecidos e trabalhados para a mitigação das graves consequências que a atingem.

Apesar da análise de soluções ser efetuada de forma comparativa, o objetivo deste artigo não está na pura indicação daquela com maior efetividade em detrimento das outras, mas sim em apontar métodos, técnicas e instrumentos que maximizem os resultados de forma viável e passível de aplicação. Busca-se sempre o convívio urbano de forma harmônica e ponderada, sem valorizar determinadas questões setoriais.

Os diversos enfoques aqui apresentados reforçam a importância de disseminar a visão holística para tratativa de problemas no ambiente urbano. $\mathrm{O}$ fato de apresentar contextualizações geográficas e soluções técnicas de drenagem em conjunto com a mobilidade urbana expressa esta forma de abordagem do objeto. Neste projeto foram apresentadas medidas estruturais e não estruturais para drenagem urbana, a partir do mesmo princípio, porém com medidas um pouco distintas. Enquanto Miguez (2001) mostra a importância de um conjunto 
de medidas componentes de um sistema indissociável, uma vez que nenhuma obra de engenharia é capaz de prever o descaso de uma população pouco preocupada com a destinação de resíduos sólidos, impermeabilização do solo e desmatamento de áreas de preservação. Ao mesmo tempo, Rio Águas (2013) apresenta uma solução também em forma de sistema, mas com um número menor de elementos capazes de concentrar maiores parcelas do problema, contudo de equilíbrio e harmonia um pouco frágeis.

Apresentar ferramentas administrativas de planejamento para obras em execução (a exemplo da comparação do projeto de Rio Águas já em execução frente ao conjunto de medidas apresentadas por Miguez) é feito propositalmente como reflexão para projetos lançados pelo governo. Algumas vezes, estes não são devidamente discutidos, bem como não são conhecidos com precisão os maiores beneficiados por essas intervenções na cidade.

Os impactos e transformações espaciais percebidos aqui não devem ser o ganho de um setor sobre o outro, como a drenagem sobre os transportes, por exemplo. De acordo com Miguez (2001) e Rossi (2003), o ganho deve ser total e acumulativo, para que, dessa maneira, a meta de qualidade de vida seja alcançada. Utilizando princípios tangíveis é possível atingir tal meta.

Ainda, percebe-se um ganho de cada solução quando são conjugadas conforme demonstrado por Bernick e Cervero (1996) e Paik (2013). A transformação de um rio em um corredor ecológico urbano permitiu não apenas que as questões de lazer e entretenimento fossem sanadas, mas também aquelas referentes à drenagem urbana, ao sistema de transporte e gestão do ambiente urbano. Ou seja, o ganho foi maximizado por focar na transversalidade da solução ao invés de sua separação em áreas técnicas.

Para manter um sistema de drenagem funcionando tal como projetado e dimensionado, de modo a manter seu papel de resguardo de segurança e saúde da comunidade circunvizinha, Hunter (1994) menciona que diversos elementos e etapas de implantação de determinada solução devem ser respeitados. Dentre estes elementos, cita-se a necessidade de preservar a capacidade pretendida de escoamento dos canais, resolver de fato a origem dos problemas de drenagem e não apenas as suas consequências, tal como não transferir problemas de montante para jusante, além de procurar reduzir necessidades e custos de manutenção de longo prazo.

\section{Referências Bibliográficas}

ABREU, Mauricio de. Evolução Urbana do Rio de Janeiro. Rio de Janeiro: IPLANRIO/Jorge Zahar Editores, 1987.

AMARANTE, Fernanda. A água no espaço urbano: uma abordagem socioambiental e sua aplicação à Grande Tijuca. Rio de Janeiro: Editora UERJ, 2006.

ANDREATTA, Verena. Cidades Quadradas, Paraísos Circulares: os planos urbanísticos do Rio de Janeiro no Século XIX. Rio de Janeiro: Editora Mauad, 2006.

BANNISTER, David. Integrated Transport: From Policy to Practice. Londres e Nova York: Routledge, 2010.

BERNICK, Michael; CERVERO, Robert. Transit Village in the 21st Century. Berkley: Editora McGraw Hill, 1996.

BRASIL, Gerson. História das ruas do Rio. Rio de Janeiro: Livraria Brasiliana Editora, 1965. 
CAMPOS, Eneida (Org.). Metodologia de gestão por processos. Campinas: Editora Unicamp, 2003. CANHOLI, Aluísio. Drenagem urbana e controle de enchentes. São Paulo: Oficina de Textos, 2005.

CEDAE (Companhia Estadual de Águas e Esgotos). Programa de Despoluição da Baía de Guanabara. Rio de Janeiro: IMPRENSA RJ, 1995.

CHIAVENATO, Idalberto. Administração Financeira: uma abordagem introdutória. Rio de Janeiro: Elsevier, 2005.

CHRISTOFOLETI, Antônio. Geomorfologia. 2. ed. São Paulo: Blucher, 1980.

CORRÊA, Roberto Lobato. Região e organização espacial. São Paulo: Ática, 2007.

D’ALTÉRIO, Carlos Fabiano. Metodologia de cenários combinados para controle de cheias urbanas com aplicação à Bacia do Rio Joana. Rio de Janeiro: Editora UFRJ, 2004.

EASLEY, David; KLEINBERG, Jon. Networks, Crowds and Markets: Reasoning About a Highly Connected World. Cambridge (Reino Unido): The Cambridge University Press, 2010.

FERRAZ, Antônio Clóvis. Transporte Público Urbano. São Carlos: Rima, 2004.

GUERRA, Antônio José (Org.). Geomorfologia Urbana. Rio de Janeiro: Bertrand Brasil, 2011.

HUNTER, Mark. Identification of Problems, Solution and Cost Savings for Maintenance of Drainage Ways. Nova York: ASCE Journal of Pipeline Systems, 1994.

IBASE (Instituto Brasileiro de Análise Sociais e Econômicas). Histórias de favelas da Grande Tijuca contadas por quem faz parte (Projeto Condutores(as) de Memórias). Rio de Janeiro: IBASE, 2006.

INEA (Instituto Estadual do Ambiente). O Estado do Ambiente: Indicadores Ambientais do Rio de Janeiro 2010. Rio de Janeiro: SEA/INEA/IMPRENSA RJ, 2011.

INEA (Instituto Estadual do Ambiente). www.inea.rj.gov.br. Acesso em 20/05/2013.

IBGE (Instituto Brasileiro de Geografia e Estatística). www.ibge.gov.br. Acesso em 20/05/2013.

INEPAC (Instituto Estadual do Patrimônio Cultural). www.inepac.rj.gov.br. Acesso em 20/05/2013.

IPP (Instituto Municipal de Urbanismo Pereira Passos). Extensão da rede hidrográfica principal, segundo os cursos d'água, com indicação das bacias hidrográficas a que pertencem. Rio de Janeiro: Diretoria de Informações Geográficas - DIG/IPP, 2005. Adaptação Disponível em: http://www.educacaopublica.rj.gov.br/oficinas/geologia/hidrografia_rj/. Acesso em 20/05/2013.

MATOS, Rosa Augusta. A gestão sustentável de recursos hídricos - experiência e desafios regionais: o caso de controle da Bacia Hidrográfica do Joana - Rio de Janeiro. Rio de Janeiro: Editora UERJ, 2004.

MIGUEZ, Marcelo. Modelo matemático de células de escoamento para bacias urbanas. Rio de Janeiro: Editora UFRJ, 2001.

PAIK, Wook Inn. Changes of Cheonggyecheon Landscape: From the Modernization Place to the Postmodern Space. Múrcia (Espanha): Notas do Congresso Cultura e Poder, 2013.

PCRJ (Prefeitura da Cidade do Rio de Janeiro). www.rio.rj.gov.br. Acesso em 20/05/2013

PREFEITURA DA CIDADE ESPECIAL DE SEUL (Seoul Teukbyeolsi). english.seoul.go.kr. Acesso em 20/05/2013.

RIO ÁGUAS. Projeto de Execução de Concepção e de Projetos de Obras Civis e Ações de Con- 
trole das Enchentes na Bacia Hidrográfica do Canal do Mangue. Rio de Janeiro: Secretaria Municipal de Obras (SMO), 2000.

ROSSI, Angela Maria Gabriella. (Org.). Ambiente Construído: reflexões sobre o desenvolvimento urbano sustentável. Rio de Janeiro: Sete Letras, 2003.

SUBSECRETARIA DE GESTÃO DAS BACIAS HIDROGRÁFICAS (Rio Águas). www.obras. rio.rj.gov.br. Acesso em 20/05/2013.

SANTOS, Carlos Nelson; BRONSTEIN, Olga. Metaurbanização: O caso do Rio de Janeiro. Revista de Administração Municipal n. 25, Rio de Janeiro, 1978.

SANTOS, Noronha. As freguesias do Rio Antigo vistas por Noronha Santos. Rio de Janeiro: Edições O Cruzeiro, 1965.

SERRANO, Carlos Alberto. Evaluación de La Movilidad em Santurce: Avenida de Diego como Eje de Integración. San Juan (Puerto Rico): Editora de la Universidad de Puerto Rico (UPR), 2005.

SILVA, Micaele. Renovação do STPU de Santa Maria/RS: Uma Nova Perspectiva para a Mobilidade Urbana. Santa Maria: Editora UFSM, 2012.

UFRJ (Universidade Federal do Rio de Janeiro). Síntese da evolução da cidade do Rio de Janeiro de acordo com a História do Brasil. Rio de Janeiro: Editora UFRJ, 2002. 